Armando Rosas González*, Dulce María Clemente Guerrero**, Edith Ramos Velasco ${ }^{* * *}$, Noemí Cruz Martínez ${ }^{* * * *}$

\title{
Diseño de estación para la rehabilitación de la motricidad en miembros superiores ${ }^{1}$
}

\author{
Design of station for rehabilitation of motor skills in upper limbs
}

\section{Cómo citar:}

Rosas, A., Clemente, D., Ramos, E. \& Cruz, N. (2019). Diseño de estación para la rehabilitación de la motricidad en miembros superiores. Designia, 7(1), 35-63.

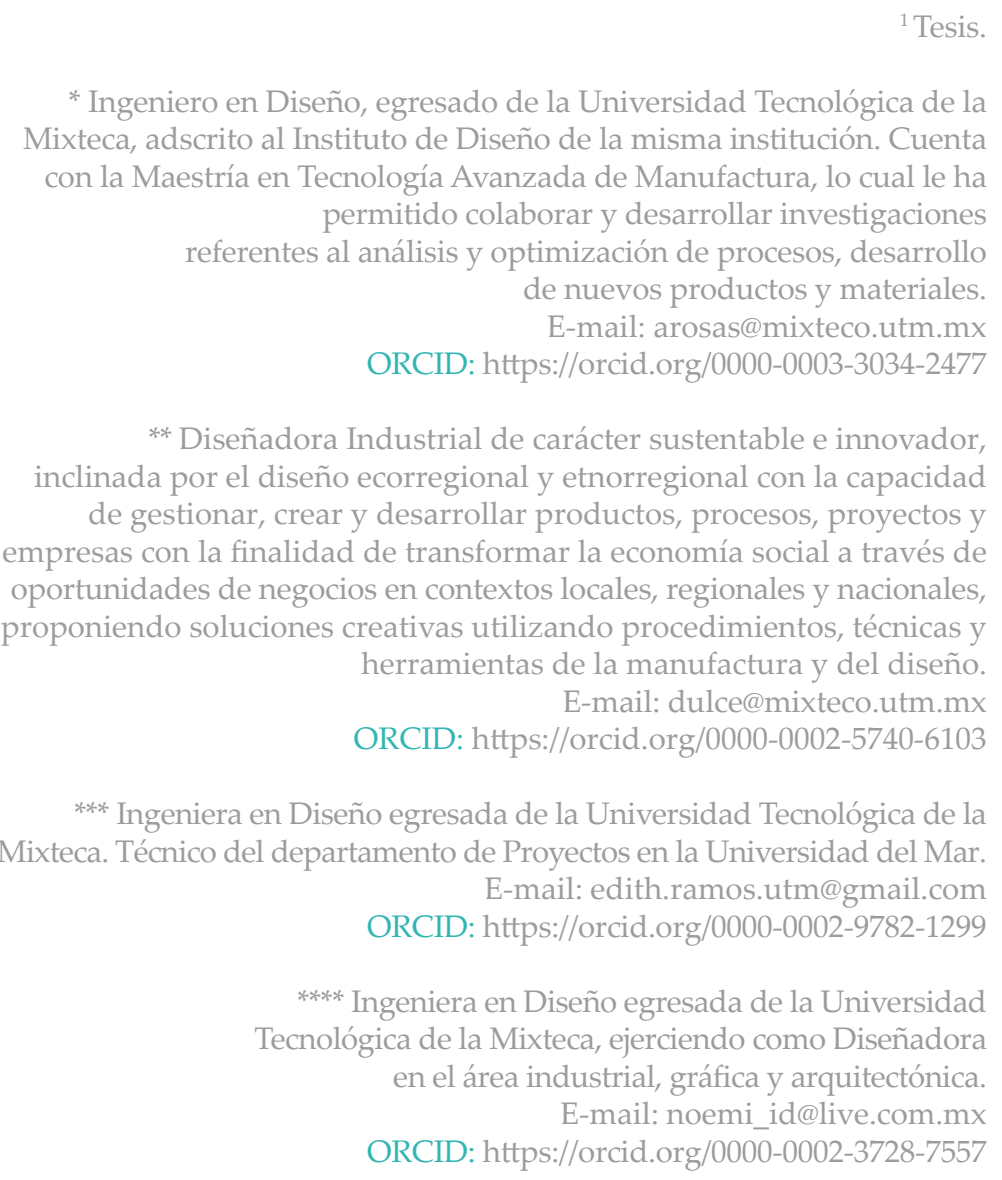

Palabras clave:

Diseño Centrado en el Usuario, terapia ocupacional, adulto mayor, ergonomía, motricidad fina, motricidad gruesa

Key words:

User-Centered Design, Occupational Therapy, older adult, human factors, fine motor skills, thick motor skills

Recibido: 04/09/2019

Aceptado: 14/11/2019 
Este artículo de investigación presenta el proyecto de diseño de una estación de terapia ocupacional para la rehabilitación de los miembros superiores en adultos mayores con discapacidad motriz. El trabajo lo efectuó un equipo interdisciplinario integrado por profesionales del diseño y del sector salud, con la colaboración de un grupo de investigación del Instituto de Diseño de la Universidad Tecnológica de la Mixteca y terapeutas ocupacionales de dos instituciones de salud localizadas en la ciudad de Huajuapan de León, Oaxaca. Para el desarrollo del proyecto se utilizó una metodología basada en la propuesta de Sevilla y González (2008), donde se abordan pautas del Diseño Centrado en el Usuario, ergonomía, antropometría y diseño sensorial, para responder a los requerimientos funcionales y formales de los usuarios. Como resultado se obtuvo un prototipo conformado por una mesa de trabajo y diversos materiales terapéuticos que sirven para la rehabilitación de habilidades motrices finas y gruesas en manos, antebrazos y brazos. Con el desarrollo de este proyecto se buscó contribuir a resolver una parte de las necesidades que tienen los profesionales en rehabilitación con adultos mayores, brindando una alternativa ante la escasa oferta de productos para terapia ocupacional que existe en México.

\section{Abstract:}

This research article presents a project where an Occupational Therapy station was designed for rehabilitate upper limbs in older adults with motor disabilities. This work was done by an interdisciplinary team of design and health professionals, through collaboration of a research group of Design Institute from the Technological University of the Mixteca and occupational therapists from two health institutions located in Huajuapan, Oaxaca. To develop this project, the methodology was based on the proposal by Sevilla \& González (2008), where guidelines of User Centered Design, human factors, anthropometry and Sensory Design are addressed, for responding to functional and formal requirements of users. The result was a prototype shaped of a work table and therapeutic materials that serve for rehabilitate fine and thick motor skills in hands, forearms and arms. With this project, a part of needs of professionals in rehabilitation with older adults was solved, providing an alternative to the limited supply of Occupational Therapy products that exists in Mexico. 


\section{INTRODUCCIÓN}

El envejecimiento es un proceso biológico ineludible que produce un detrimento en las funciones psicomotoras del ser humano, afectando su capacidad de interactuar con los objetos y espacios cotidianos al realizar actividades de la vida diaria. Una de las áreas encargadas de contribuir a resarcir el deterioro psicomotriz en los adultos mayores (AM) es la terapia ocupacional (TO), la cual se define como "el uso terapéutico de actividades de autocuidado, trabajo y juego para incrementar la función independiente, mejorar el desarrollo y prevenir la discapacidad" (Polonio, Durante y Noya, 2001).

El proceso de involución psicomotriz generado en la vejez trae consigo algunas patologías propias de la edad como el mal de Parkinson y la artritis, entre otras, cuyas consecuencias implican alteraciones motoras tales como hemiplejias y modificaciones en la marcha, así como alteraciones en los miembros superiores (Chapinal, 2005; Landinez, Contreras y Castro, 2012). La TO representa una alternativa terapéutica no agresiva para el mantenimiento del estado cognitivo y psicomotriz en los AM, que evita el uso de tratamientos farmacológicos (Colunga, Reymundo, Valdes y Alonso, 2014).

La discapacidad es más frecuente entre los AM que en el resto de la población: en México, alrededor del $27 \%$ de AM tienen alguna dificultad para realizar actividades de autocuidado como caminar, vestirse, alimentarse, bañarse o levantarse de la cama. Las más comunes de las disfunciones motrices que presentan los AM y que requieren rehabilitación mediante $\mathrm{TO}$ son las generadas en los miembros superiores (brazo, antebrazo y mano), las cuales afectan las habilidades motrices finas y gruesas (Sedesol, Segob e Inapam, 2017). 
En México, la oferta de productos para realizar actividades terapéuticas mediante TO es limitada. Usualmente, estos productos brindan una apariencia tosca y desordenada. Asimismo, resultan económicamente inaccesibles a los terapeutas ocupacionales, ya que la mayoría deben encargarse específicamente con empresas extranjeras. Debido a esto, es común que los terapeutas ocupacionales adapten o elaboren ellos mismos los objetos y mobiliario que utilizan en la rehabilitación con AM; estos elementos tienen una imagen poco profesional, y su funcionalidad es limitada (Benítez, 2005). Además, la burocracia y los recursos limitados en las instituciones públicas de salud también dificultan el acceso a estos productos (Sedesol, Segob e Inapam, 2017).

Con base en lo anterior, un grupo de investigación del Instituto de Diseño de la Universidad Tecnológica de la Mixteca desarrolló este proyecto, con el objetivo de diseñar una estación de TO para AM a partir de las necesidades particulares que fueron identificadas en las áreas de rehabilitación del Centro Integral de la Familia del Sistema Nacional para el Desarrollo Integral de la Familia (DIF) y en la Unidad de Consulta Externa del Instituto Mexicano del Seguro Social (IMSS), localizadas en la ciudad de Huajuapan de León, Oaxaca.

La estación está integrada por tres módulos de TO para la rehabilitación de habilidades relacionadas con la motricidad fina y gruesa en los miembros superiores, tales como la coordinación manual, la coordinación óculo-manual y la coordinación grafoperceptiva; tiene además una mesa con superficie de trabajo de altura regulable y compartimentos para almacenar los materiales terapéuticos.

Con este proyecto se pretende resaltar la importancia que tiene la aplicación de conceptos del Diseño Centrado en el Usuario, la ergonomía, la antropometría y las pautas del diseño sensorial, para responder a los requerimientos funcionales y formales propios de este tipo de productos, atendiendo al contexto específico para el cual fueron diseñados. También, con esta investigación se pretende enfatizar la importancia del trabajo interdisciplinario del equipo de desarrollo conformado por ingenieros en diseño, diseñadores industriales y terapeutas ocupacionales. Asimismo, se buscó generar una alternativa ante la escasa oferta de productos para TO que existe en México y brindar una solución a las falencias de los objetos que actualmente se ocupan, contribuyendo a resolver una parte de las necesidades que tienen los profesionales en rehabilitación con AM. 
Para cubrir los requerimientos funcionales y estéticos del producto a diseñar, acorde a las necesidades de la investigación, se adaptó la metodología propuesta por Sevilla y González (2008), la cual plantea un abordaje del proyecto de diseño desde el análisis del sistema usuario-producto-contexto. Esta metodología utiliza como base el conocimiento de la realidad social y funcional de los AM, elementos de ergonomía y de Diseño Centrado en el Usuario, para desarrollar productos que aseguren un entorno seguro y accesible, mejorando la calidad de vida del usuario con dependencia funcional. A continuación se mencionan las técnicas, los procedimientos y las etapas de la metodología empleada.

Fase 1. Identificar: Se determinaron las necesidades del proyecto, a partir de los siguientes aspectos: i) Identificación de usuarios y descripción de sus características; ii) Realización de visitas a los centros de salud, para observar los equipos y materiales con que se desarrolla la TO con AM; iii) Entrevista a terapeutas ocupacionales encargados de realizar la rehabilitación y a pacientes AM; iv) Análisis de las características funcionales y estéticas de estaciones para TO ya existentes en el mercado; v) Revisión de la literatura referente a las características antropométricas de la población mexicana de AM; vi) Análisis de normas aplicables al diseño de ayudas técnicas, diseño de mobiliario y de objetos para AM.

Fase 2. Evaluar: Se determinaron requerimientos funcionales y estéticos para el proyecto, a partir de la información obtenida en la fase anterior y de los siguientes aspectos: i) Aplicación del método Kano para jerarquizar las necesidades identificadas; ii) Desarrollo de la primera fase del Despliegue de la Función de la Calidad $(\mathrm{DFC})$, para la definición de los requerimientos de diseño del proyecto.

Fase 3. Integrar: Se desarrollaron alternativas de diseño de la estación de TO para AM mediante el bocetaje y la aplicación de la técnica de creatividad denominada "Pregunte, pregunte, pregunte". Estas ideas se trabajaron y evolucionaron hasta la obtención de la propuesta final. Posteriormente, se elaboró el modelo 3D virtual de la alternativa final.

Fase 4. Elaborar: Se fabricó un prototipo a escala 1:1 de la estación de TO para AM a partir de los siguientes aspectos: i) Análisis estático de cargas, para comprobar la resistencia de algunos elementos de la estación de TO para AM mediante el Análisis de Elemento Finito (AEF); ii) Generación de los planos constructivos de la propuesta final.

Fase 5. Validar: Se realizaron evaluaciones para verificar la usabilidad, seguridad, funciones y dimensiones de la estación de TO para AM. 


\section{RESULTADOS}

\subsection{Fase 1. Identificar}

En esta etapa se comenzó por la identificación de usuarios. Los usuarios primarios son los AM, hombres y mujeres de 65 o más años de edad, quienes utilizarán el producto en forma directa realizando las actividades de TO. Los AM pueden presentar disfunciones motrices en los miembros superiores debidas a trastornos físico-periféricos presentes en articulaciones, huesos y músculos, ocasionados por patologías como la artritis reumatoidea y traumatismos generados por accidentes, golpes o quemaduras. Por otro lado, aparecen trastornos neurológicos ocasionados por el deterioro del sistema nervioso, accidentes vasculares o lesiones cerebrales, los cuales producen deficiencias motoras a causa de patologías como la hemiplejía, hemiparesia, cuadriparesia, cuadriplejía, esclerosis múltiple o Parkinson.

En ambos casos pueden presentarse disfunciones motrices en miembros superiores, como alteraciones del tono muscular (espasticidad, flacidez, rigidez en músculos), alteraciones de la sensibilidad (anestesia, hipoestesia, hiperestesia), alteraciones en la coordinación (distonía) y alteraciones físicas (deformidad en articulaciones de los dedos de la mano, traumatismos). El segundo tipo de usuarios considerados en el proyecto implica a los terapeutas ocupacionales, profesionales de ambos sexos que se encargan de planificar y apoyar la ejecución de la TO con los AM. Serán las personas que también se encargarán de limpiar, transportar y dar mantenimiento al material y mobiliario de la estación de TO.

A continuación, se realizó un análisis con respecto al estado del arte de las estaciones de TO para AM, examinando el mobiliario y los materiales terapéuticos que las conforman. Se encontró que la situación de los terapeutas ocupacionales y del sistema de salud en México es similar al de otros países, principalmente de Latinoamérica. Existe una escasa oferta de productos para efectuar la rehabilitación de AM mediante TO, ya que la mayoría se fabrican en Estados Unidos y China; esto requiere que se importen específicamente, lo cual incrementa significativamente su costo. Ante esto, también en otras naciones los terapeutas ocupacionales generalmente se ven en la necesidad de elaborar sus propios materiales terapéuticos, reutilizando materiales, objetos de otros ámbitos, etc.

Se encontraron las siguientes características comunes en las estaciones de TO para AM analizadas: i) Son mobiliarios que poseen ruedas para poder desplazarlos, cuentan con un tablero en donde se colocan los materiales terapéuticos y entrepaños, 
repisas o contenedores para almacenarlos; ii) Tienen una imagen tosca y desordenada, cuentan con elementos abatibles que permiten ocupar un mayor espacio durante las terapias, pero no tienen las dimensiones y disposiciones adecuadas para que los pacientes efectúen la rehabilitación de forma cómoda; iii) Algunas de las estaciones tienen un sistema que permite regular la altura de la mesa de trabajo y de los elementos para almacenar los materiales terapéuticos, si bien su estructura no posibilita que el terapeuta ocupacional atienda de manera frontal al paciente; 4) No cuentan con elementos que sirvan como soporte a los AM para sostenerse, sentarse o levantarse; 5) Tienen una variedad de materiales terapéuticos para ejercitar distintas habilidades mediante la TO, objetos que son llamativos y estimulantes, pero poco prácticos para almacenarse; 6) Existen materiales terapéuticos que se pueden adquirir por separado, pero son caros y difíciles de conseguir en México.

Por otro lado, también se analizaron algunos proyectos académicos desarrollados en diferentes países, en donde se generaron productos para la rehabilitación de los miembros superiores en AM mediante TO. Por ejemplo, en Argentina se diseñó una estación multifuncional de estimulación motriz, con diferentes elementos y actividades para el tratamiento de personas con diferentes disfunciones en los miembros superiores. El producto consiste en placas plegables que pueden estructurarse en diferentes configuraciones, habilitando las diferentes actividades (González y Soto, 2009).

En Colombia se diseñó un objeto lúdico que permite la estimulación de la memoria a corto plazo en los AM a través de la asociación de gráficos relacionados con actividades y objetos cotidianos. En la misma investigación se desarrolló un mobiliario que integra superficies intercambiables con diferentes juegos de mesa (Sevilla y González, 2008).

En Ecuador se diseñaron diversos objetos lúdicos para la estimulación de la psicomotricidad fina y gruesa de AM en un centro gerontológico. El primer producto consiste en una barra para efectuar giros con la cadera y extender los brazos, la cual también puede reproducir sonidos al colocar semillas secas en su interior. El segundo objeto es un conjunto de piezas que se ensamblan con hilo para formar un teléfono. El tercer producto es un mecanismo que produce una melodía mediante el movimiento circular de los pies con un pedal (Roldán, 2014). 
En Brasil se diseñaron cuatro dispositivos para la fabricación de alfombras que se ocupan en las actividades de TO con AM en un hospital psiquiátrico. El primer dispositivo incluye un guante, una aguja, un gancho y una base que facilitan el bordado. El segundo producto consiste en una aguja con un mango ergonómico y un caballete que sirve como apoyo del brazo y almacén de agujas. El tercer dispositivo es un telar diseñado para AM con visión disminuida y temblores en las manos. El cuarto producto es un soporte para tijeras, el cual disminuye el esfuerzo para efectuar cortes (Franck, Díaz y Domenech, 2017).

En México se diseñó un dispositivo que permite efectuar cinco diferentes ejercicios (flexo-extensores de dedos, escalerilla de dedos y hombro, patineta, timón, pronosupinador) en brazos y manos para personas con osteoartritis (Benítez, 2005). En estos proyectos descritos, puede observarse que son diferentes los contextos y los tipos de objetos que se han generado para atender la rehabilitación de los miembros superiores mediante TO para AM, desarrollándose desde mobiliario hasta material terapéutico que integra diversas actividades. Igualmente, estos proyectos aún no se han comercializado, y por lo tanto no están al alcance de los terapeutas ocupacionales.

Posteriormente, se aplicaron entrevistas abiertas a terapeutas ocupacionales (dos del DIF y tres del IMSS) y a cinco pacientes AM; también se observaron las características y condiciones del mobiliario y materiales con los que se desarrollan las actividades de TO para AM en el Centro Integral de la Familia del DIF y en la Unidad de Consulta Externa del IMSS que se localizan en la ciudad de Huajuapan de León. Se identificó que durante las terapias se ocupan camillas y mesas que no cuentan con las configuraciones y dimensiones antropométricas adecuadas para el desarrollo de las actividades (figura 1). Los pacientes generalmente efectúan la rehabilitación adoptando una posición sedente en sillas de las clínicas; sin embargo, en algunos casos se requiere colocar almohadas en el asiento y respaldo para que puedan estar cómodos. 


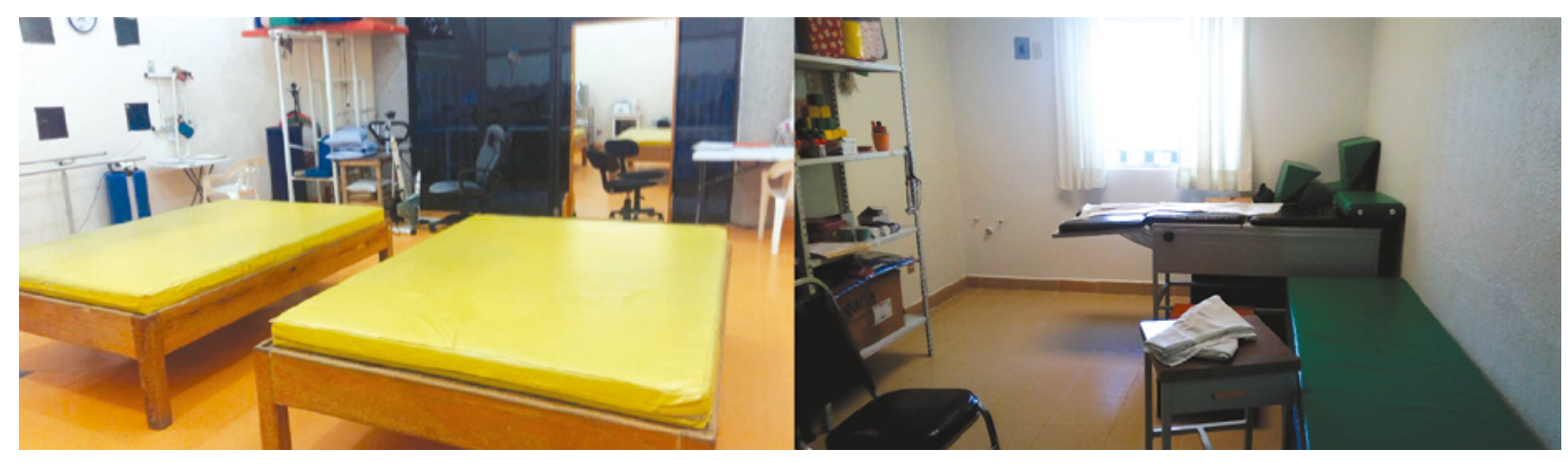

Figura 1. Sala de mecanoterapia del DIF y sala principal del área de rehabilitación del IMSS.

Fuente: Elaboración propia, 2018.

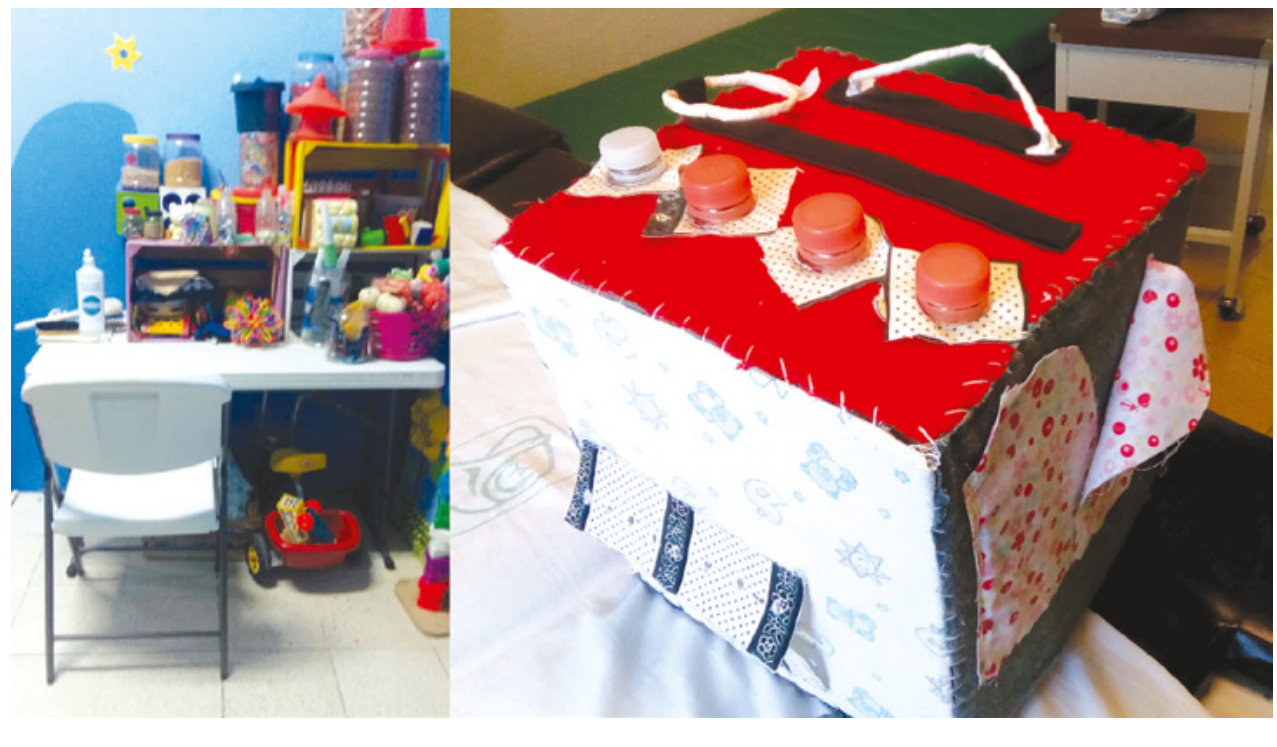

Figura 2. Material de sala multisensorial y cubo multifuncional hecho de materiales reutilizados. Fuente: Elaboración propia, 2018.

También se observó que en ambas instituciones los terapeutas ocupacionales generalmente elaboran su propio material, lo cual brinda a los objetos una apariencia poco profesional y estimulante (figura 2). Se emplean juguetes y objetos pertenecientes a otros ámbitos para desarrollar la rehabilitación (semillas, utensilios de cocina, etc.). Además, los materiales para TO se desorganizan y extravían fácilmente, ya que no se cuenta con un mobiliario que se haya diseñado específicamente para ello. La vida útil de los materiales y del mobiliario es corta, pues se usan materiales de deficiente calidad y poca durabilidad. 
Los pacientes entrevistados manifestaron que generalmente asisten a las terapias en compañía de algún familiar cercano (pareja, hijos). Mencionaron que en la mayoría de las ocasiones les resulta incómodo realizar las terapias, debido a que el mobiliario no cuenta con las dimensiones adecuadas. También dijeron que el uso de camillas como superficie de trabajo es poco funcional, ya que los objetos se resbalan, y no tienen el espacio suficiente para aproximarse a los materiales terapéuticos, ni para trabajar cercanamente con el terapeuta ocupacional. Indicaron que debido a sus padecimientos se les dificulta sentarse o levantarse de la mesa de trabajo y ejecutar algunos ejercicios. Además, expresaron que en algunas ocasiones ellos proporcionan materiales (ganchos para ropa, plastilina, etc.) para el desarrollo de las terapias.

Asimismo, los pacientes elogiaron la labor que realizan los terapeutas ocupacionales, resaltaron la creatividad que tienen para planificar y elaborar tanto las actividades como los materiales terapéuticos, a pesar de las carencias que existen en las instituciones donde acuden. Finalmente, mencionaron que les agrada poco la apariencia del mobiliario y de algunos materiales, ya que tienen un aspecto simple, poco ortopédico y nada atractivo, lo cual les motiva poco a utilizarlos.

De acuerdo con las entrevistas hechas a los terapeutas ocupacionales, se identificó que el mobiliario y materiales específicos para TO comúnmente les resultan inaccesibles, ya que la mayoría son productos extranjeros que requieren encargarse especialmente, además de que tienen un alto costo. Mencionaron que la burocracia presente en las instituciones responsables dificulta la adquisición de estos productos. Por otro lado, dijeron que a raíz del sismo ocurrido en septiembre de 2017 (Nolasco, 2017), las áreas y servicios para TO en ambas instituciones estuvieron inhabilitadas durante algunos meses debido a los daños sufridos en su infraestructura; por ello tuvieron dificultades para retomar las actividades con los AM, ya que debían trasladar el mobiliario y materiales a otros espacios, lo cual resultó complicado debido a que no contaban con una estación para TO que fuese fácil de transportar.

También los terapeutas ocupacionales indicaron que los AM se distraen, se frustran o se enojan cuando no efectúan exitosamente los ejercicios, por lo que requieren motivarlos continuamente. Expresaron que los materiales terapéuticos se almacenan en bolsas, en tinas o en cajas de diferentes materiales. Además, mencionaron que normalmente cada uno establece las actividades y ejercicios acorde a la condición de cada paciente. Dijeron que el servicio de TO tiene una alta demanda, a pesar de las limitaciones con las que laboran, alcanzando a atender cada uno hasta 40 pacientes de forma individual en una semana. 
Asimismo, los terapeutas ocupacionales indicaron que las disfunciones motrices en los miembros superiores (brazo, antebrazo y mano) son las más frecuentes y recurrentes en los AM, y debido a esto efectúan algunos ejercicios como: limpiar superficies, efectuando diferentes trayectorias de movimientos; pasar objetos de un extremo de la mesa a otro; enrollar hilos en conos; subir cierres y abrochar botones; modelar diferentes figuras usando plastilina; ensartar aros, entrelazar objetos y apilar cubos.

Los terapeutas ocupacionales expresaron que requieren desinfectar continuamente tanto el mobiliario como los materiales terapéuticos que ocupan, y resaltaron la importancia de ejercitar en los AM las habilidades motrices finas y gruesas de los miembros superiores, ya que intervienen en el desarrollo de actividades básicas de la vida diaria (ABVD) como alimentarse, vestirse y asearse, además de que influyen en actividades instrumentales de la vida diaria (AIVD) como la preparación de alimentos, las compras, el uso de elementos de comunicación, la limpieza y el mantenimiento del hogar.

\subsection{Fase 2. Evaluar}

Posteriormente, de manera consensuada entre el grupo de investigación y los terapeutas ocupacionales participantes, se desarrolló el método Kano con el fin de jerarquizar las necesidades identificadas en la fase anterior, para después definir los requerimientos funcionales y estéticos a través de la primera etapa del DFC. De esta manera se perfilaron las oportunidades de diseño que se describen a continuación, con el objetivo de mejorar la rehabilitación de AM mediante TO en las instituciones del caso de estudio.

Primero, se planteó el diseño de un mobiliario para realizar actividades y ejercicios de TO con AM en posición sedente, que facilite la interacción frente a frente entre el paciente y el terapeuta, posibilite su traslado a través de diversos espacios, y se adapte a las características antropométricas del grupo etario considerado, ocupando 
un espacio mínimo en los consultorios. El mobiliario debe incluir elementos para organizar y almacenar de forma práctica los materiales terapéuticos, servir como soporte para que los AM puedan sentarse o ponerse de pie, y además estar fabricado con materiales resistentes al uso continuo que permitan su fácil mantenimiento, con un diseño que aliente a los AM a usarlo.

En segundo lugar, se proyectó el diseño de un conjunto de materiales terapéuticos para la rehabilitación de la motricidad fina y gruesa de los miembros superiores en pacientes AM que padecen diversas patologías. Los materiales terapéuticos deben presentar un diseño que estimule su uso, integrando actividades y ejercicios con diferentes niveles de dificultad para la rehabilitación de los movimientos básicos del brazo, antebrazo y mano, mediante actividades en donde se trabajen la coordinación manual, la coordinación óculo-manual y la coordinación grafoperceptiva.

La Asociación Americana de Terapia Ocupacional (AOTA) agrupa en seis categorías a los componentes del marco de trabajo para la práctica de la TO, entre las cuales se encuentran las habilidades motoras, entendidas como capacidades que involucran movimiento personal o movimiento de objetos (Fisher, 2003). La motricidad gruesa comprende la capacidad del cuerpo para integrar el trabajo de los músculos largos, con el objeto de realizar determinadas actividades como saltar, correr, trepar, bailar, etc. La motricidad fina abarca todas aquellas tareas que requieren precisión, destreza y un elevado nivel de coordinación. En los miembros superiores, además de dominio muscular y coordinación en los movimientos, tanto la motricidad fina como gruesa precisan de una coordinación entre el ojo y las manos, para dirigirlas correctamente hacia el objeto que se desea tomar, o para realizar actividades como escribir, coser, etc. (Pacheco, 2015).

La coordinación manual se manifiesta en movimientos cuya ejecución requiere la participación de las dos manos y de sus dedos. La coordinación óculo-manual implica una mayor complejidad que la anterior, ya que todas las tareas exigen un análisis perceptivo o un apoyo visual como condición clave para que las manos sean capaces de realizar movimientos guiados mediante percepciones visuales. Entre las actividades más frecuentes que conciernen a la coordinación óculo-manual se encuentran punzar, enhebrar, recortar, moldear y pintar objetos. En la coordinación grafoperceptiva, además del dominio muscular y motor, intervienen el análisis perceptivo y el dominio de un instrumento $\mathrm{u}$ objeto, habilidades que permiten obtener una respuesta gráfica sobre una superficie y comprobar la relación entre el resultado plasmado y los estímulos observados (Comellas y Perpinyá, 2003). 
Estas tres formas de acción casi nunca se realizan de forma individual, sino que aparecen combinadas en el funcionamiento de los miembros superiores (Galeno, 2005; Huayama, 2016). De acuerdo con los terapeutas ocupacionales que colaboraron en la investigación, la ejecución constante y progresiva de los ejercicios utilizando los materiales terapéuticos proyectados influirá en la mejora de las habilidades motoras finas y gruesas, y por ende, en el desarrollo de las ABVD y las AIVD de los AM.

\subsection{Fase 3. Integrar}

En esta fase, con la colaboración de los integrantes del grupo de investigación y los terapeutas ocupacionales participantes, se elaboraron alternativas para el diseño de la estación de TO para AM mediante el desarrollo de bocetos que incluyeron la descripción de los distintos atributos funcionales y estéticos. Las propuestas se obtuvieron a través de la aplicación de la técnica de creatividad "Pregunte, pregunte, pregunte" propuesta por Ingledew (2016). Las alternativas se mejoraron gradualmente hasta la obtención de la versión final, de la cual se elaboró un modelo 3D virtual usando el software Solidworks®.

Para la determinación de las características estéticas de la estación de TO se tomaron como referencia las siguientes pautas, brindadas por Bedolla (2002) y Moore, Pearce \& Applebaum (2010), para el diseño de productos enfocados en AM: i) La forma debe explicar claramente la función del objeto; ii) Uso de elementos que permitan proteger la salud y bienestar físico del individuo, integrando elementos que habiliten su transportación y movilidad; iii) Uso de colores limpios, que permitan altos contrastes, generando sensaciones de tranquilidad, confort, seguridad y afabilidad; iv) Diseño de formas y texturas que brinden agarre y estabilidad extra. La estación de TO para AM proyectada está compuesta por dos subsistemas: materiales terapéuticos y mesa de trabajo.

\subsubsection{Materiales terapéuticos.}

Los materiales terapéuticos se organizaron en tres módulos, los cuales permiten ejercitar la coordinación manual, la coordinación óculo-manual y la coordinación grafoperceptiva a través de diferentes actividades. Para su proyección se tomaron en cuenta las recomendaciones de diseño brindadas en la "Norma UNE-EN 527-1:2001. Mobiliario de oficina. Mesas de trabajo" (Corregidor, 2010; Sevilla, 2011; Zaragoza, 
Costa, Rando y Aguilar, 2015). Los datos antropométricos de referencia se obtuvieron del estudio hecho por Ávila, Prado y González (2007). Los materiales terapéuticos se componen de tableros y piezas para ejercicios o actividades.

Los tableros están hechos con lámina de polietileno de alta densidad (HDPE) de $1 / 2$ ", de color azul, con esquinas y cantos redondeados, mientras que las piezas para ejercicios o actividades fueron impresas con diferentes formas y colores en acrilonitrilo butadieno estireno (ABS), mediante impresión 3D, usando la tecnología de modelado por deposición fundida (FDM), debido a su costo accesible y facilidad de producción. Se usaron colores contrastantes, y se evitó modelar elementos de tamaño significativamente pequeño debido a la disminución en las capacidades visuales de los AM; además, se incluyeron cantos, bordes y formas redondeadas para prevenir lesiones durante su manejo.

\section{a. Módulo de coordinación manual.}

El módulo de coordinación manual permite realizar diferentes movimientos guiados con una o ambas manos en un tablero de $35 \times 25 \mathrm{~cm}$ (figura 3a). Con la guía ubicada en la parte superior se trabajan movimientos circulares con una o ambas manos, con la de la parte intermedia se realizan movimientos escalonados o de flexión y extensión de la muñeca, y con la que está situada en la parte inferior se efectúan movimientos lineales y longitudinales.

El módulo de coordinación manual incluye tres piezas distintas:

- La primera pieza tiene un radio de $2 \mathrm{~cm}$ y un espesor de $3 \mathrm{~mm}$. Permite realizar agarres bidigitales, con los dedos índice y anular, tanto como de pinza fina, de manera cómoda e intuitiva (figura 3b).

- La segunda pieza tiene un diseño esférico en dos tamaños para efectuar agarres usando 2 o 3 dedos (figura 3c). La pieza esférica pequeña tiene un diámetro de $2 \mathrm{~cm}$, permitiendo hacer agarres tridigitales, mientras que la pieza grande tiene un diámetro de $5 \mathrm{~cm}$, y posibilita realizar agarres bi y tridigitales.

- La tercera pieza tiene un diámetro de $7 \mathrm{~cm}$, y posee un cinturón de velcro ajustable que permite rodear la mano de cualquier persona para realizar agarres palmares (figura 3d). 


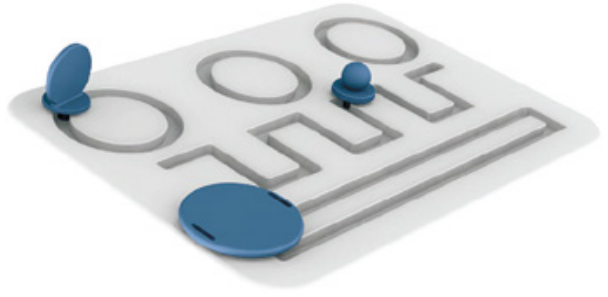

Figura $3 a$

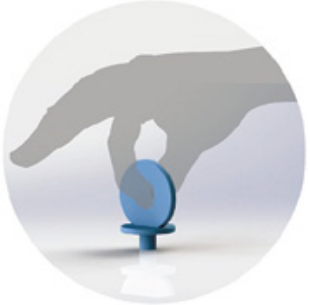

Figura 3b

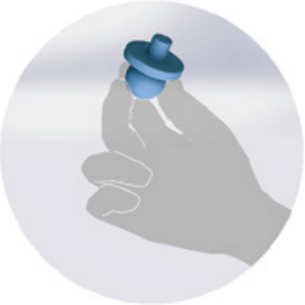

Figura 3c

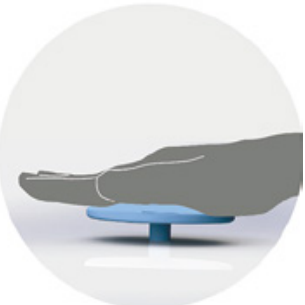

Figura 3d

Figura 3a. Elementos del módulo de coordinación manual; figura 3b. Pieza para agarres bidigitales; figura 3c. Pieza para agarres bi y tridigitales; figura 3d. Pieza para agarre palmar. Fuente: Elaboración propia, 2018.

\section{b. Módulo de coordinación óculo-manual.}

El módulo de coordinación óculo-manual está integrado por conectores de $2.6 \mathrm{~cm}$ de diámetro; tubos para ensamblar, de 5, 10 y $15 \mathrm{~cm}$ de largo y $2.2 \mathrm{~cm}$ de diámetro; gotitas de $3 \mathrm{~cm}$ de diámetro; aros pasaguía de $5 \mathrm{~cm}$ de diámetro; y un tablero de $25 \times 30 \mathrm{~cm}$ con perforaciones circulares de $2.2 \mathrm{~cm}$ de diámetro. Permite desarrollar cuatro actividades:

- Actividad 1: Para desarrollarla se utilizan 18 tubos de tres tamaños distintos y el tablero (figura 4a). El paciente debe colocar las piezas en las perforaciones del tablero, acomodándolas por color o por tamaño. Con este módulo se trabajan habilidades de motricidad fina al tomar y mover las piezas en el tablero, y se ejercita la fuerza de los miembros superiores al colocar las piezas en la perforación para que encajen.

- Actividad 2: En esta actividad intervienen 24 piezas (6 gotitas de cada color) y el tablero (figura $4 \mathrm{~b}$ ). El paciente debe colocar las piezas en las perforaciones del tablero, acomodándolas por color o generando figuras específicas. Los pacientes ejercitan la fuerza de los miembros superiores al tomar las piezas con la mano cerrada, y trabajan la coordinación al mover las piezas con ambas manos a distintas alturas o distancias para colocarlas en el tablero perforado. 
- Actividad 3: En esta actividad se usa una cantidad variable de cordones en color rojo, amarillo, azul, verde, naranja y morado, además del tablero (figura 4c). El paciente debe enhebrar los cordones en las perforaciones del tablero, formando distintos patrones geométricos y trabajando la coordinación de los movimientos de los miembros superiores, particularmente la desviación radial y cubital de la muñeca. Las perforaciones son lo suficientemente amplias para que ensarten los cordones aquellos AM que presentan debilidad visual o temblores en las manos.

- Actividad 4: En esta actividad se usa el tablero y una cantidad variable de tubos para ensamblar, además de conectores y aros pasaguía de diferentes colores (figura $4 \mathrm{~d}$ ). El paciente debe ensamblar los tubos y los conectores sobre el tablero para formar distintas estructuras y pasar el aro a través de ellas. Con esta actividad se trabajan agarres y movimientos como pronosupinación de la muñeca y circunducción del hombro al pasar el aro por los tubos ensamblados.

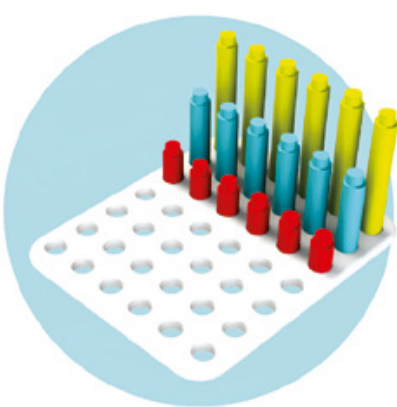

Figura 4a

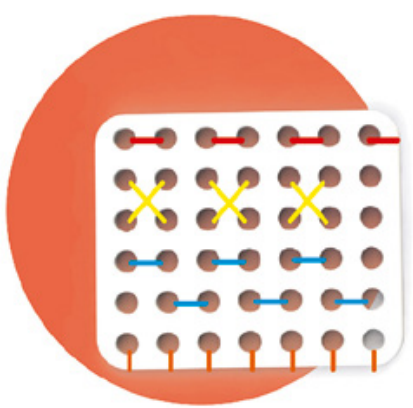

Figura 4c

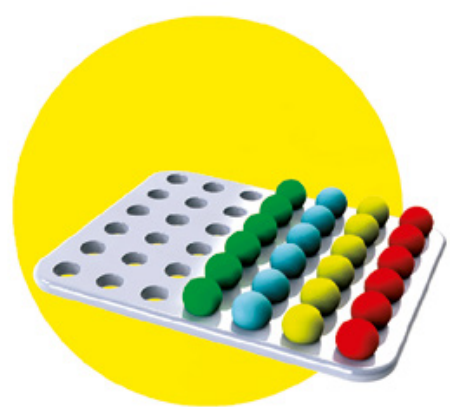

Figura 4b

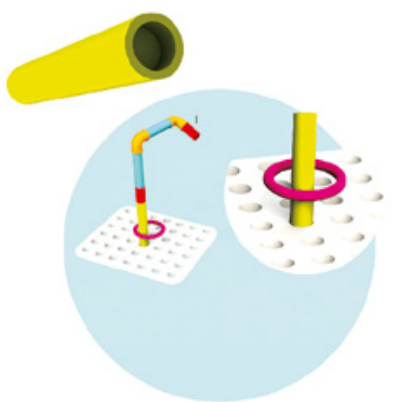

Figura $4 d$

Figura 4a. Elementos de la actividad 1; figura $4 \mathrm{~b}$. Elementos de la actividad 2; figura 4c. Elementos de la actividad 3; figura $4 \mathrm{~d}$. Elementos de la actividad 4. 


\section{c. Módulo de coordinación grafoperceptiva.}

El módulo de coordinación grafoperceptiva consiste en un pizarrón de $40 \times 30 \mathrm{~cm}$ y un marcador de tinta borrable, en cuyo centro se coloca una hoja con elementos visuales (letras, figuras, formas, etc.) que el paciente deberá reproducir (figura 5). Con esta actividad se trabaja la coordinación óculo-manual mediante gráficos que sirven como guías, además de que se ejercita la fuerza manual al tener que sujetar y desplazar el marcador.

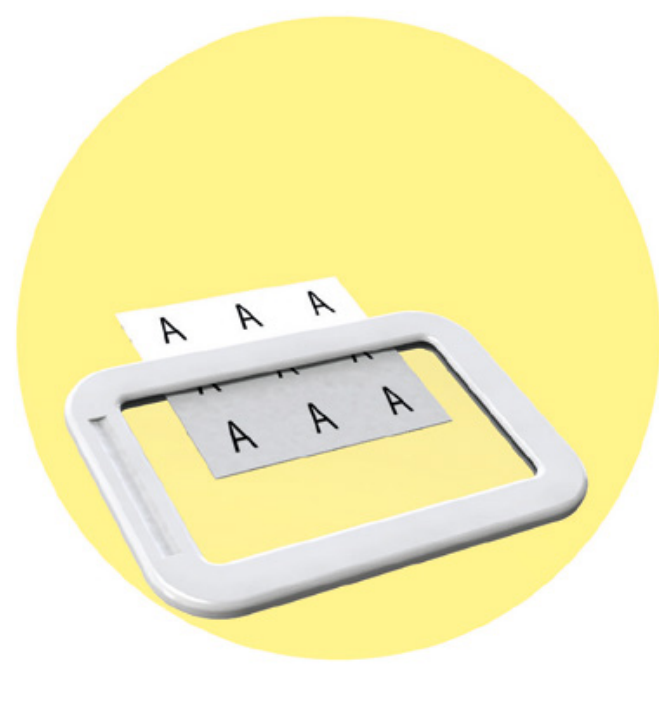

Figura 5. Elementos del módulo de coordinación grafoperceptiva. Fuente: Elaboración propia, 2018. 


\subsubsection{Mesa de trabajo.}

La mesa de trabajo se diseña de tal forma que permite la interacción frente a frente del paciente con el terapeuta ocupacional durante las sesiones de rehabilitación (figura 6). Para su proyección se consideraron las pautas de diseño brindadas por García, Moraga, Page, Tortosa y Verde (1992), la “Norma UNE-EN 527-1:2001. Mobiliario de oficina. Mesas de trabajo" (UNE, 2001) y las "Fichas guía de diseño universal de mobiliario" (Aidima y Via Libre, 2015). Los datos antropométricos de referencia se obtuvieron del estudio hecho por Ávila, Prado y González (2007).
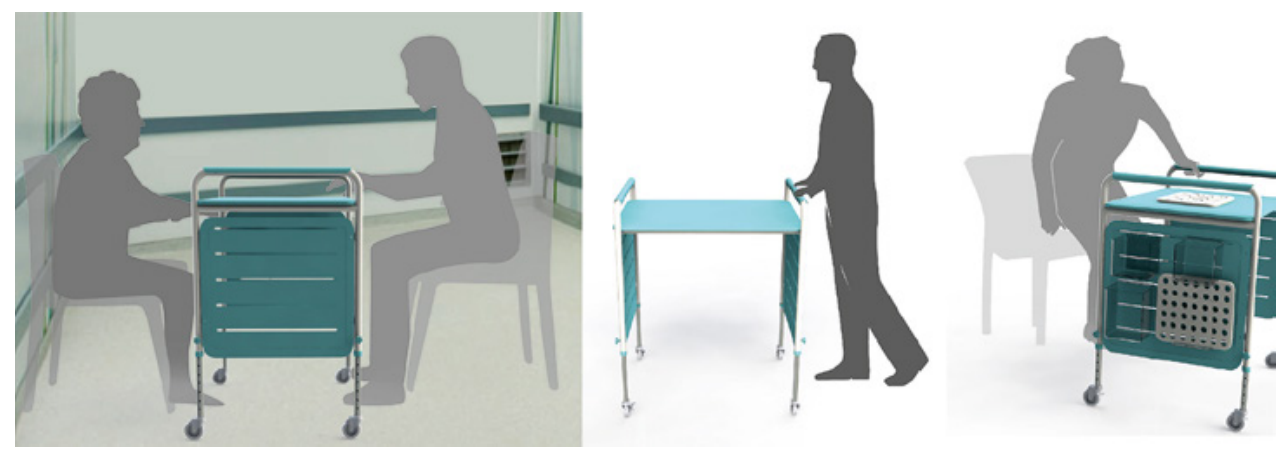

Figura 6. Mesa de trabajo de la estación de TO para AM. Fuente: Elaboración propia, 2018.

La mesa se concibe como un mobiliario móvil que puede trasladarse a través de diversos espacios, tiene ruedas con freno que giran $360^{\circ}$ sobre su eje y posee un mecanismo telescópico manual para ajustar la altura del tablero. Además, cuenta con soportes laterales para que los AM puedan sostenerse, sentarse o levantarse. Este mueble posee paneles laterales con ranuras que sirven para colocar los contenedores de las piezas y tableros que constituyen los materiales terapéuticos (figura 7). 

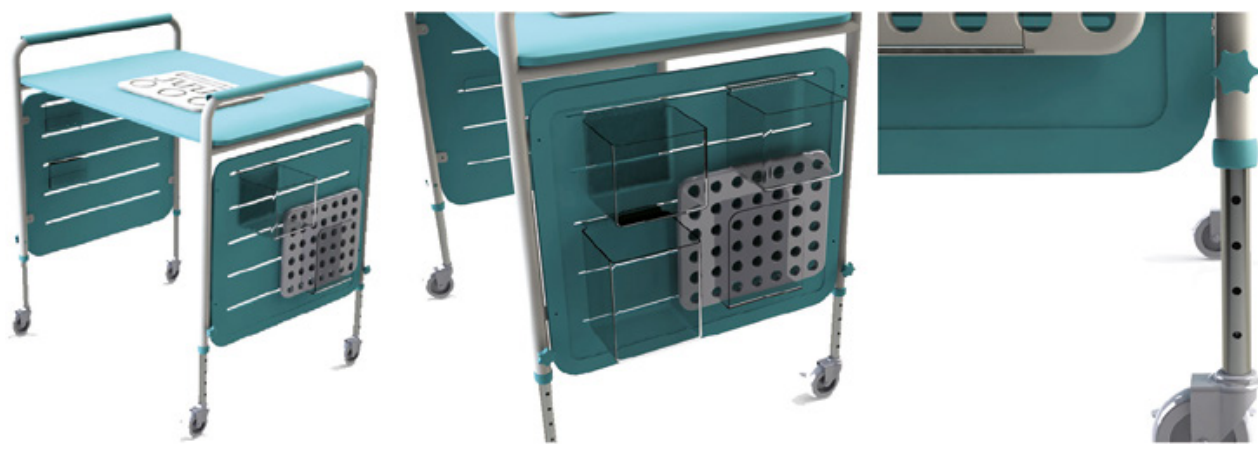

Figura 7. Elementos de la mesa de trabajo. Fuente:

Elaboración propia, 2018.

La estructura de la mesa está armada con tubo industrial cédula 5 de 3/4", excepto en las patas, donde se utilizó tubo industrial cédula 5 de $1 / 2$ " para generar el mecanismo de ajuste de altura, y cuenta con un acabado de pintura electroestática color blanco. Las dimensiones de la mesa son de $70 \mathrm{~cm}$ de largo (percentil 5 de anchura entre codos, AM del sexo femenino) y $70 \mathrm{~cm}$ de ancho (percentil 95 de alcance frontal de brazo, AM del sexo masculino). La altura del tablero de la mesa se ajusta en un rango entre 56 a $75 \mathrm{~cm}$ (percentil 5 de altura de codo en posición sentada, AM del sexo femenino, y percentil 50 de altura de codo en posición sentada, adulto del sexo masculino, respectivamente). La altura de los soportes laterales puede ajustarse en un rango de $71 \mathrm{a} 90 \mathrm{~cm}$ (percentil 5 de altura codo flexionado, adulto del sexo femenino); estos vienen con una agarradera ergonómica de ABS.

Las ruedas giratorias de caucho poseen un diámetro de 3" y tienen la capacidad para trasladar un peso total de $220 \mathrm{~kg}$, incluyendo el peso propio del mueble, de los materiales terapéuticos y de un AM del sexo masculino de $95.2 \mathrm{~kg}$ (considerando el percentil 95). Tanto el tablero de la mesa como los paneles laterales de almacenamiento están hechos con lámina de HDPE de $1 / 2$ ", color azul, con esquinas y cantos redondeados. El mecanismo de ajuste de altura tiene perforaciones a cada $30 \mathrm{~mm}$ y cuenta con una perilla de ajuste. Las uniones en la estructura metálica se hicieron con soldadura de electrodo revestido, mientras que los ensambles de los paneles laterales de almacenamiento y el tablero de la mesa con la estructura metálica se realizaron con tornillos de acero de $1 / 4^{\prime \prime}$ x $3 / 4^{\prime \prime}$.

Los paneles laterales poseen ranuras horizontales en 5 niveles que permiten generar distintas distribuciones, pudiéndose colocar hasta 6 contenedores en cada uno de ellos, de acuerdo con las necesidades de los terapeutas ocupacionales, y se encuentran unidos a la estructura principal de la mesa de trabajo para que puedan moverse de forma simultánea con el tablero. 
Los contenedores para los materiales terapéuticos están hechos de acrílico transparente de $3 \mathrm{~mm}$ de espesor, tienen forma prismática y esquinas redondeadas, además de que poseen una pestaña que permite engancharlos verticalmente por las partes internas o externas en las ranuras de los paneles laterales. Se proyectaron de tres tipos: el primer y segundo contenedor miden $15 \times 12 \mathrm{~cm}$ (figura 8a) y $13 \times 21$ $\mathrm{cm}$ (figura 8 b) respectivamente, y ambos se utilizan para almacenar las piezas para ejercicios o actividades. Las dimensiones del tercer contenedor son 15 x $18 \mathrm{~cm}$, y se ocupa para guardar los tableros (figura 8c).

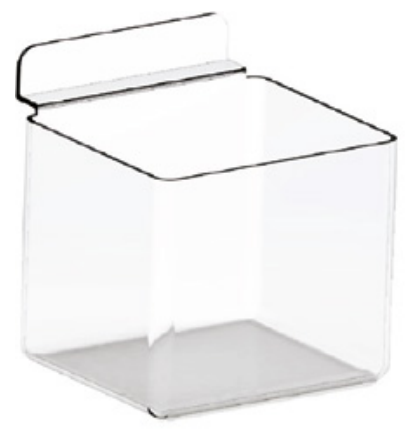

Figura 8a

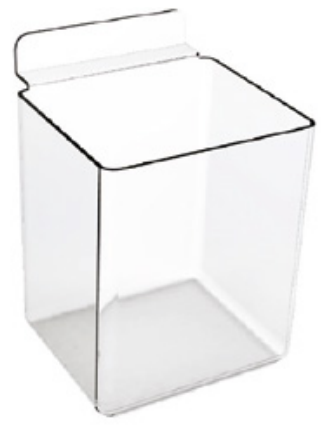

Figura 8b

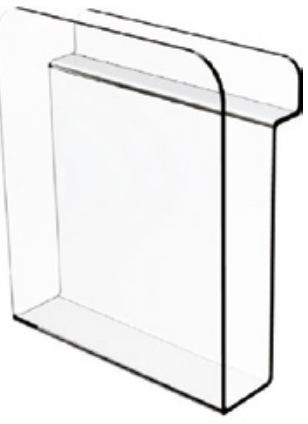

Figura 8c

Figura 8a. Contenedor chico;

figura 8b. Contenedor grande; figura 8c. Contenedor para tableros. Fuente: Elaboración propia, 2018. 
Se realizó una simulación de Análisis de Elemento Finito (AEF) por medio del software Solidworks ${ }^{\circledR}$, para evaluar la resistencia de los materiales propuestos en la fabricación de un prototipo de alta fidelidad de la estación de TO para AM (figura 9).
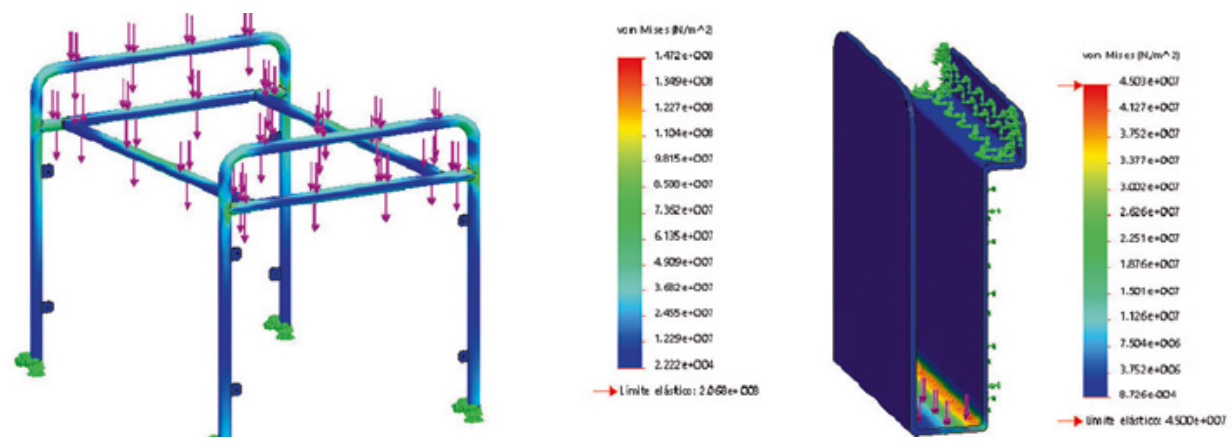

Figura 9. Simulación mediante AEF. Fuente: Elaboración propia, 2018.

En las simulaciones hechas con la estructura metálica, los contenedores, los tableros de la mesa y de almacenamiento (tabla 1), se obtuvo que el valor de esfuerzo de Von Mises generado por las cargas aplicadas fue menor al límite elástico de los materiales propuestos, lo cual es un indicativo de que los componentes no se romperían. De la misma manera, se obtuvieron valores mayores a 1 del factor de seguridad, lo cual también mostró que los elementos resistirían las cargas consideradas.

\begin{tabular}{|c|c|c|c|c|c|}
\hline Elemento & Carga aplicada $(\mathrm{kg})$ & $\begin{array}{c}\text { Limite elástico del } \\
\text { material }\left(\mathrm{N} / \mathrm{m}^{2}\right)\end{array}$ & $\begin{array}{c}\text { Esfuerzo de Von } \\
\text { Mises }\left(\mathrm{N} / \mathrm{m}^{2}\right)\end{array}$ & $\begin{array}{c}\text { Factor de } \\
\text { Seguridad }\end{array}$ & $\begin{array}{c}\text { Carga máxima que } \\
\text { soportará }(\mathrm{kg})\end{array}$ \\
\hline Estructura metálica & 92.5 & $2.068 \times 10^{8}$ & $1.472 \times 10^{8}$ & 1.4 & 129.5 \\
\hline $\begin{array}{c}\text { Contenedor chico para } \\
\text { materiales terapéuticos }\end{array}$ & 2.28 & $4.5 \times 10^{7}$ & $1.956 \times 10^{7}$ & 2.3 & 5.244 \\
\hline $\begin{array}{c}\text { Contenedor grande para } \\
\text { materiales terapéuticos }\end{array}$ & 3.21 & $4.5 \times 10^{7}$ & $2.812 \times 10^{7}$ & 1.6 & 5.136 \\
\hline Contenedor para tableros & 1.8 & $4.5 \times 10^{7}$ & $1.551 \times 10^{7}$ & 2.9 & 5.22 \\
\hline Tablero de la mesa & 92.5 & $1.5 \times 10^{7}$ & $9.375 \times 10^{6}$ & 1.6 & 148 \\
\hline Paneles laterales & 22.8 & $1.5 \times 10^{7}$ & $2.343 \times 10^{6}$ & 6.4 & 145.92 \\
\hline
\end{tabular}

Tabla 1. Valores obtenidos en la simulación mediante AEF. 
También se fabricó un prototipo de alta fidelidad de la estación de TO para AM en los talleres de la Universidad Tecnológica de la Mixteca (figura 10). Durante el proceso de fabricación del prototipo se identificó que el mobiliario y materiales terapéuticos desarrollados podrían manufacturarse a gran escala mediante el uso de máquinas de control numérico y de inyección de plástico, lo cual a su vez podría reducir los costos de producción.

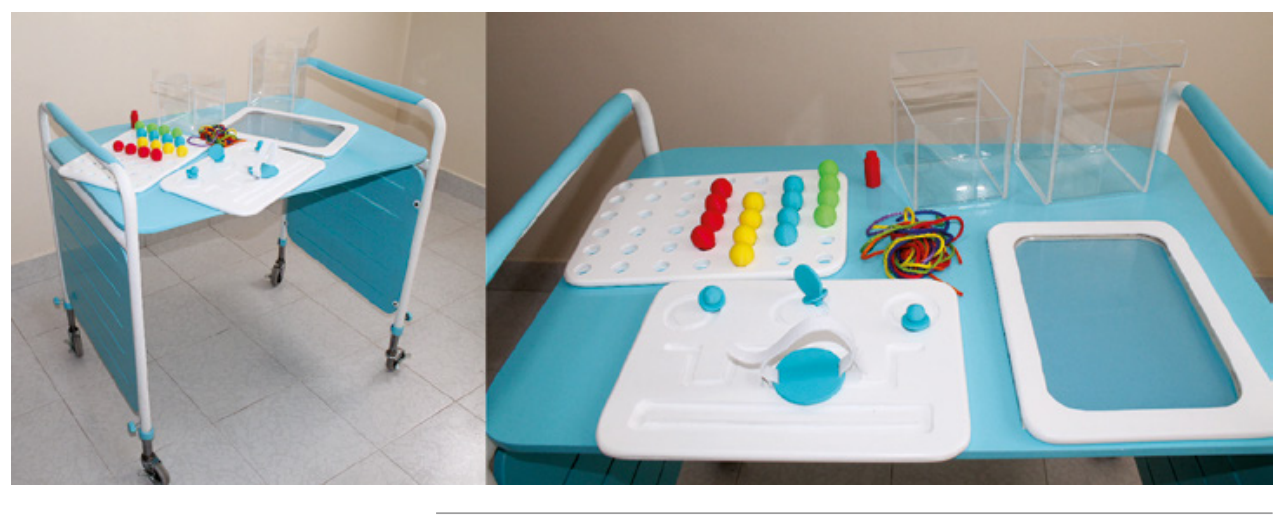

Figura 10. Prototipo de alta fidelidad de la estación de TO para AM. Fuente: Elaboración propia, 2018.

\subsection{Fase 5. Validar}

Se hizo una prueba del prototipo con base en el "Protocolo de Descubrimiento Conjunto" (Andreau et al., 2003), con la colaboración de una terapeuta ocupacional y un paciente AM que padece Parkinson en una etapa avanzada, para examinar los atributos funcionales y estéticos de la estación de TO (figura 11).

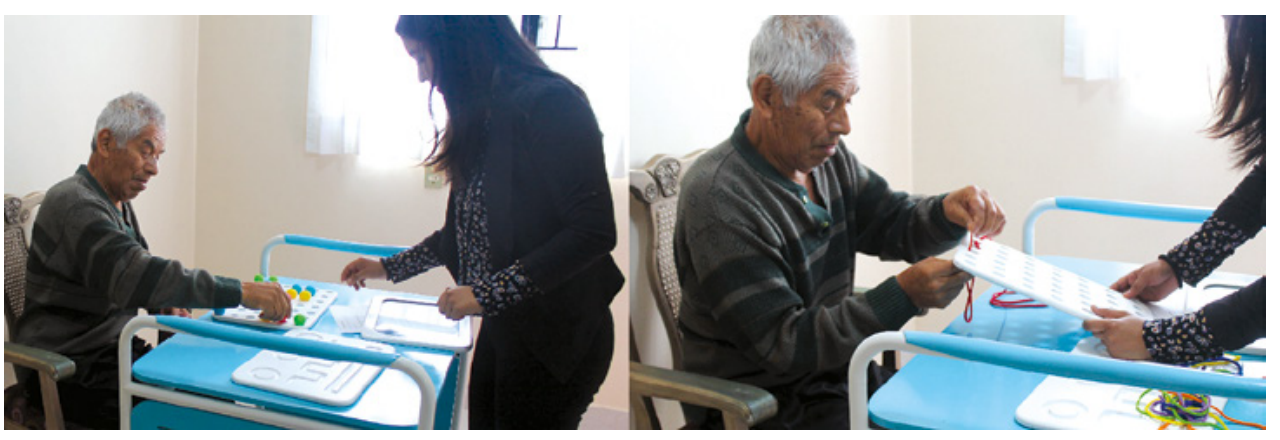

Figura 11. Desarrollo de la prueba con el prototipo. Fuente: Elaboración propia, 2018. 
La terapeuta ocupacional desarrolló con el paciente una sesión de aproximadamente 60 minutos de duración, donde ambos ocuparon los materiales terapéuticos y la mesa de trabajo. Al final de la prueba, se solicitó a los colaboradores que emitieran su opinión acerca de las características de la estación mediante una entrevista abierta. De acuerdo con la terapeuta ocupacional, el transporte de la estación le resultó cómodo, ya que los apoyos laterales tienen la altura adecuada. Expresó que la distancia a la que se encuentran los contenedores de los materiales terapéuticos y su peso son convenientes para evitar hacer esfuerzos considerables. También afirmó que el diseño de la mesa de trabajo y de los materiales terapéuticos le resultaron atractivos por las formas, colores y dimensiones aplicadas.

Además, la terapeuta ocupacional opinó que las actividades dispuestas a través de los materiales terapéuticos resultarán útiles para efectuar la rehabilitación en AM de las habilidades motoras finas y gruesas en miembros superiores. Expresó que el diseño de la estación le permitirá tener una interacción frente a frente con los pacientes, lo cual resulta benéfico en la medida en que podrá visualizar que las actividades se efectúen adecuadamente y alentar a los AM. Afirmó que posteriormente sería recomendable hacer algunos cambios en el mecanismo de ajuste de altura, para que pudiera calibrarse sin requerir del apoyo de otra persona e identificar más fácilmente la posición precisa para colocar la perilla.

También ella expresó que los materiales utilizados en la fabricación de la estación facilitarán su mantenimiento y prolongarán su uso durante las terapias. Señaló que los materiales terapéuticos permitirán realizar actividades y ejercicios con distintos grados de dificultad, lo cual se ajusta a las diferentes condiciones de salud de los pacientes. Destacó que sería bueno que posteriormente se incluyeran materiales terapéuticos adicionales para ejercitar otras habilidades motoras (facial, gestual y fonética). Finalmente, resaltó que durante su trayectoria profesional nunca había tenido a su alcance un producto similar, y que posteriormente le gustaría adquirirlo.

Por su parte, el paciente manifestó que la mesa de trabajo le pareció estable, y que los apoyos laterales le sirvieron adecuadamente para sentarse y levantarse de su silla. También señaló que los materiales terapéuticos y el mobiliario le parecieron seguros y cómodos para su uso, y que las formas y colores implementados le resultaron agradables, por lo cual se sintió muy motivado a utilizarlos. Durante el desarrollo de la prueba se observó que el paciente se agotó luego de efectuar las actividades con los módulos de coordinación manual y óculo-manual, por lo que se prescindió de utilizar el módulo de coordinación grafoperceptiva. 
Posteriormente, se le permitió ocupar a la terapeuta ocupacional la estación de TO durante un periodo de 15 días, para que continuara evaluando con los pacientes sus características funcionales y estéticas. Al final de la etapa de pruebas se le pidió que respondiera un cuestionario basado en la escala de Likert (donde 1 indica el nivel de satisfacción más bajo y 5 el más alto), para conocer su grado de satisfacción con el desempeño, tanto de la mesa de trabajo como de los materiales terapéuticos (tablas 2 y 3). Puede observarse que la mayoría de los aspectos evaluados obtuvieron la calificación más alta posible.

\begin{tabular}{|c|c|c|c|c|}
\hline \multirow{2}{*}{ La mesa de trabajo } & \multicolumn{4}{|c|}{ Escala de respuestas } \\
\hline & \begin{tabular}{|l|l|l|l}
1 & 2 \\
\end{tabular} & 3 & 4 & 5 \\
\hline Permite ajustar fácilmente la altura de la superficie de trabajo & & $*$ & & \\
\hline Es fácil de limpiar y desinfectar & & & * & \\
\hline Es estable & & & & $*$ \\
\hline Es resistente al uso continuo & & & & $*$ \\
\hline Es fácil de transportar & & & & * \\
\hline Su tamaño es adecuado para el espacio donde se usa y se guarda & & & & * \\
\hline Me parece atractiva visualmente & & & * & \\
\hline El área de trabajo me parece adecuada para realizar las terapias & & & & . \\
\hline Los espacios para guardar los tableros, los contenedores y las piezas pequeñas son suficientes & & & & * \\
\hline Me agradan sus colores & & & & * \\
\hline
\end{tabular}

Tabla 2. Evaluación de la mesa de trabajo. Fuente: Elaboración propia, 2018.

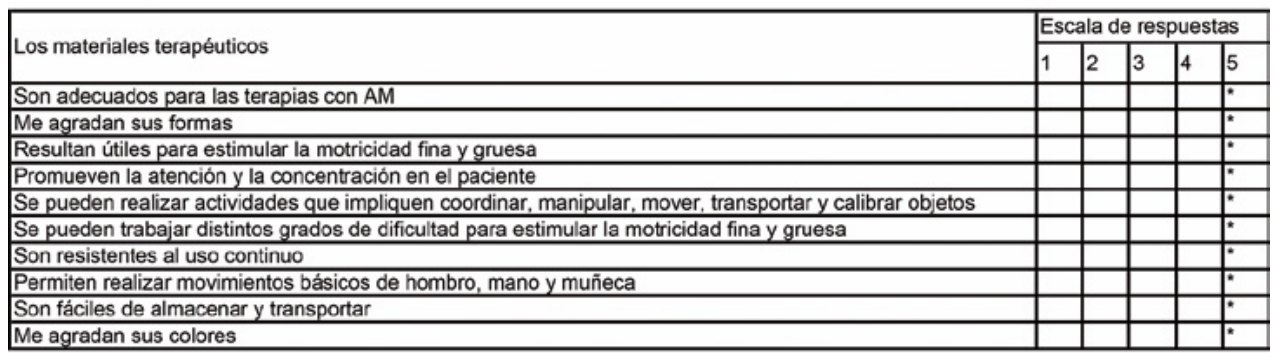

Tabla 3. Evaluación de los materiales terapéuticos. Fuente: Elaboración propia, 2018. 


\section{DISCUSIÓN Y CONCLUSIONES}

El objetivo principal de este proyecto consistió en diseñar una estación de TO para la rehabilitación de los miembros superiores en AM con discapacidad motriz. La investigación desarrollada aporta ampliamente a partir de los resultados proyectuales obtenidos, ya que se diseñó un conjunto de materiales terapéuticos para la rehabilitación de la motricidad fina y gruesa, los cuales integran actividades y ejercicios con distintos niveles de dificultad, en donde se ejercitan la coordinación manual, la coordinación óculo-manual y la coordinación grafoperceptiva; esto permite ocuparlos en pacientes con diferentes condiciones de salud. También, exhiben formas llamativas y colores contrastantes que estimula su uso con los AM. Los materiales terapéuticos poseen el tamaño adecuado e incluyen cantos, bordes y formas redondeadas que hacen cómodo y seguro su manejo con los pacientes. Además, están hechos con materiales que facilitan su mantenimiento y garantizan su durabilidad.

Conjuntamente, se diseñó una mesa de trabajo que ocupa un espacio mínimo en los consultorios y tiene contenedores en donde se almacenan los materiales terapéuticos; esto brinda un mayor orden en los espacios de rehabilitación. También cuenta con un mecanismo para ajustar la altura del tablero y tiene apoyos laterales para que los AM puedan sostenerse, sentarse o levantarse, lo cual da mayor confort y seguridad a los usuarios. Además, la mesa de trabajo puede trasladarse a través de diversos espacios, haciéndola versátil ante contingencias que se susciten o en caso de que la rehabilitación deba efectuarse en diferentes sitios de las clínicas. Asimismo, permite la interacción frente a frente entre los usuarios, lo cual permite que el terapeuta ocupacional visualice la manera como se desarrollan los ejercicios y aliente a los pacientes durante la rehabilitación.

Del mismo modo, la formulación metodológica desarrollada en esta investigación aporta de manera importante, impactando en una necesidad real mediante la aplicación de un proceso de Diseño Centrado en el Usuario que fue complementado con pautas ergonómicas, antropométricas y sensoriales. Para resolver la problemática abordada, primero se analizaron algunas estaciones de TO para AM que se comercializan en diferentes partes del mundo, además de proyectos académicos en donde se han generado productos para la rehabilitación de los miembros superiores mediante TO. Se encontró que estos productos difícilmente están al alcance de los terapeutas ocupacionales y de las instituciones que brindan estos servicios, debido a que deben importarse mediante pedidos específicos o no se encuentran disponibles en el mercado. 
También se halló que estas circunstancias orillan a los terapeutas ocupacionales a producir sus propios materiales terapéuticos y a usar mobiliario que se les proporciona en las clínicas; no obstante, se encontró que estos objetos poseen vastas deficiencias que dificultan el desarrollo de las terapias y que motivan poco a los AM para realizarlas. A pesar de esto, se reconoció que la terapia ocupacional es una labor que tiene una alta flexibilidad para que los profesionales planeen e implementen actividades acordes a su criterio, experiencia y recursos con los que cuentan. Además, se identificó que existe un amplio conjunto de oportunidades futuras para que profesionales del diseño y de la salud generen interdisciplinariamente soluciones que mejoren las condiciones de vida de los AM, ya que se calcula que en México serán el grupo con crecimiento demográfico más importante en décadas posteriores, cuadruplicando su cantidad hacia el año 2050 (González, 2013; Martínez, 2007).

Como trabajo futuro se espera continuar con el diseño de materiales terapéuticos que complementen a los obtenidos en este proyecto, de modo que sirvan para rehabilitar otras habilidades motoras. También se desea analizar a largo plazo el impacto de la estación de TO en la rehabilitación de los AM en las instituciones del caso de estudio. Además, se espera optimizar el diseño de la estación de TO para que pueda ser ocupada por usuarios de otras condiciones de vida y edades. 


\section{REFERENCIAS BIBLIOGRÁFICAS}

Aidima y Vía Libre (2015). Fichas guía de diseño universal de mobiliario. Recuperado de: https://sid.usal. es/idocs/F8/FDO19231/fichas_guia_mobiliario.pdf

Andreau, M., Barberá, R., Cort, J. M., López, M. A., Poveda, R., Sánchez, J. J., Prat, J. M. y Ramiro, P. (2003). ¿Cómo obtener productos con alta usabilidad? Guía práctica para fabricantes de productos de la vida diaria y ayudas técnicas. Valencia: Fundación CEDAT-Instituto de Biomecánica de Valencia.

Ávila, R., Prado, L. R. y González, E. L. (2007). Dimensiones antropométricas de la población latinoamericana: México, Cuba, Colombia, Chile. Guadalajara: Universidad de Guadalajara.

Bedolla, D. (2002). Diseño sensorial, las nuevas pautas para la innovación, especialización, y personalización del producto [Tesis doctoral]. Recuperado de: http://upcommons.upc.edu/handle/2117/94136

Benítez, A. (2005). Diseño de artefacto médico funcional para ser aplicado en la terapia ocupacional de las personas de la tercera edad aquejadas por osteoartritis en brazos y manos [Tesis de pregrado]. Recuperado de: http://jupiter.utm.mx/ tesis_dig/9749.pdf

Colunga, Z., Reymundo, M., Valdes, M. V. y Alonso, J. (2014). Terapia ocupacional en el adulto mayor como estrategia para prevenir el deterioro cognitivo. Revista Electrónica de Investigación en Enfermería FESI-UNAM, 3(6), 28-41. Recuperado de: http://www.revistas.unam.mx/index.php/cuidarte/article/ download/69085/60910 
Comellas, J. M. y Perpinyá, A. (2003). Aspectos básicos del desarrollo infantil y propuestas para favorecer el aprendizaje escolar. Barcelona: Ediciones CEAC.

Corregidor, A. I. (2010). Terapia Ocupacional en Geriatría y Gerontología. Bases conceptuales y aplicaciones prácticas. Madrid: Sociedad Española de Geriatría y Gerontología.

Chapinal, A. (2005). Entrenamiento de la independencia en Terapia Ocupacional; rehabilitación en la hemiplejia, ataxia, traumatismos craneoencefálicos y en las involuciones del anciano. Barcelona: Masson.

Fisher, A. (2003). Assessment of Motor and Process Skills: Volume 1: Development, Standardization, and Administration Manual. New York: Three Star Press Inc.

Franck, R., Díaz, E. A. y Domenech, S. (2017). Design of Assistive Devices and Occupational Therapy: Case Study in a Brazilian Psychiatric Hospital. Advances in Ergonomics in Design, 588, 529-540. doi: 10.1007/978-3-319-60582-1_53

Galeno, M. (2005). La importancia de la psicomotricidad y el juego como un medio para desarrollar la lectoescritura [Tesis de pregrado]. Recuperado de: http://200.23.113.51/pdf/22660.pdf

García, C., Moraga, R., Page, A., Tortosa, L. y Verde, V. (1992). Guía de recomendaciones para el diseño de mobiliario ergonómico. Valencia: Instituto de Biomecánica de Valencia.

González, S. (2013). Padecimientos más frecuentes que condicionan discapacidad en pacientes adultos mayores que acuden al centro de rehabilitación e integración social de Cuautitlán Izcalli en el año 2011 [Tesis de pregrado]. Recuperado de: http://ri.uaemex.mx/handle/20.500.11799/14330

González, P. y Soto, M. (2009). Diseño de una Estación de Estimulación para Terapia Ocupacional [Tesis de pregrado]. Recuperado de: http://diana.fadu.uba.ar/67/

Huayama, Y. del C. (2016). Eficacia del programa "Me divierto mirando lo que hacen mis manitas" en el desarrollo de la coordinación viso manual, en niños y niñas de 4 años, del nivel inicial del colegio adventista "El Buen Maestro" de Quillabamba-Cusco-2014 [Tesis de pregrado]. Recuperado de: http:// repositorio.upeu.edu.pe/handle/UPEU/170

Ingledew, J. (2016). Cómo tener ideas geniales, guía para el pensamiento creativo. Barcelona: Editorial Blume.

Landinez, N. S., Contreras, K. y Castro, A. (2012). Proceso de envejecimiento, ejercicio y fisioterapia. Revista Cubana de Salud Pública, 38(4), 562-580. doi: 10.1590/S0864-34662012000400008 
Martínez, C. M. (2007). Organización de un centro de día para el adulto mayor [Tesis de pregrado]. Recuperado de: http://www.bib.uia.mx/tesis/pdf/014881/014881.pdf

Moore, M. W., Pearce, A. y Applebaum, S. (2010). Sensación, significado y aplicación del color. Santiago: LFNT.

Nolasco, D. (20 de septiembre de 2017). Huajuapan de León registra el mayor daño por el sismo de 7.1 en Oaxaca con más de 500 viviendas afectadas. ADN Sureste. Recuperado de: http://www.adnsureste. info/huajuapan-de-leon-registra-el-mayor-dano-por-el-sismo-de-7-1-en-oaxaca-con-mas-de-500viviendas-afectadas-1445-h/

Pacheco, G. (2015). Psicomotricidad en Educación Inicial: Algunas consideraciones conceptuales. Quito: Formación Académica № 1 .

Polonio, B., Durante, P. y Noya, B. (2001). Conceptos fundamentales de terapia ocupacional. Madrid: Editorial Médica Panamericana.

Roldán, E. R. (2014). Objetos lúdicos para la estimulación psicomotriz de los adultos mayores en el centro gerontológico "Hogar de Ancianos Sagrado Corazón de Jesús" [Tesis de pregrado]. Recuperado de: http://repositorio.pucesa.edu.ec/handle/123456789/1006

Sedesol, Segob e Inapam (2017). Programa Nacional Gerontológico 2016-2018. Recuperado de: http://www. gob.mx/cms/uploads/attachment/file/265503/PROGRAMA_NACIONAL_GERONTOLOGICO_5_ ENERO_2017.pdf

Sevilla, G. A. (2011). La naturaleza relacional entre la discapacidad y el diseño: modelo sistémico de análisis persona en situación de discapacidad - entorno construido [Tesis de maestría]. Recuperado de: http://repositoriocdpd.net:8080/handle/123456789/233

Sevilla, G. A. y González, J. F. (2008). Ergonomía de concepción objetos de apoyo para adultos mayores. Revista Iconofacto, 5(4), 66-98. Recuperado de: https://revistas.upb.edu.co/index.php/iconofacto/ article/view/3059

UNE (2011). Norma UNE-EN 527-1:2001. Mobiliario de oficina. Mesas de trabajo. Recuperado de http:// www.une.org

Zaragoza, R., Costa, M., Rando, N. y Aguilar, T. (2015). Diseño para todos en juegos, juguetes y videojuegos. Madrid: Ceapat-Imserso. 